Article

\title{
Digital Design, Analysis and 3D Printing of Prosthesis Scaffolds for Mandibular Reconstruction
}

\author{
Khaja Moiduddin *(D), Syed Hammad Mian $\mathbb{D}^{\mathbb{D}}$, Hisham Alkhalefah and Usama Umer $\mathbb{D}$
}

Advanced Manufacturing Institute, King Saud University, Riyadh 11421, Saudi Arabia;

syedhammad68@yahoo.co.in (S.H.M.); halkhalefah@ksu.edu.sa (H.A.); usamaumer@yahoo.com (U.U.)

* Correspondence: kmoiduddin@gmail.com; Tel.: +96-611-469-7372

Received: 21 March 2019; Accepted: 14 May 2019; Published: 16 May 2019

Abstract: Segmental mandibular reconstruction has been a challenge for medical practitioners, despite significant advances in medical technology. There is a recent trend in relation to customized implants, made up of porous structures. These lightweight prosthesis scaffolds present a new direction in the evolution of mandibular restoration. Indeed, the design and properties of porous implants for mandibular reconstruction should be able to recover the anatomy and contour of the missing region as well as restore the functions, including mastication, swallowing, etc. In this work, two different designs for customized prosthesis scaffold have been assessed for mandibular continuity. These designs have been evaluated for functional and aesthetic aspects along with effective osseointegration. The two designs classified as top and bottom porous plate and inner porous plate were designed and realized through the integration of imaging technology (computer tomography), processing software and additive manufacturing (Electron Beam Melting). In addition, the proposed designs for prosthesis scaffolds were analyzed for their biomechanical properties, structural integrity, fitting accuracy and heaviness. The simulation of biomechanical activity revealed that the scaffold with top and bottom porous plate design inherited lower Von Mises stress (214.77 $\mathrm{MPa}$ ) as compared to scaffold design with inner porous plate design (360.22 MPa). Moreover, the top and bottom porous plate design resulted in a better fit with an average deviation of $0.8274 \mathrm{~mm}$ and its structure was more efficiently interconnected through the network of channels without any cracks or powder material. Verily, this study has demonstrated the feasibility and effectiveness of the customized porous titanium implants in mandibular reconstruction. Notice that the design and formation of the porous implant play a crucial role in restoring the desired mandibular performance.

Keywords: mandibular reconstruction; scaffolds; reconstruction plate; finite element analysis; 3D printing; titanium alloy

\section{Introduction}

Mandibular reconstruction is recognized as the most challenging and significant procedures by maxillofacial surgeons. It can be attributed to the strict requirements demanded by patients, in terms of anatomy, outer profile of the mandible and optimal restoration of oral functions [1-4]. The problem of mandibular reconstruction is further escalated owing to a rapid increase in mandibular defects due to modern human skeletal diversity and chewing behavior [5]. Generally, the mandibular continuity defect involves a complete bone loss and is caused by infection, trauma, lesion, osteonecrosis and resection of benign and malignant tumors [1]. The timely and adequate rehabilitation of mandibular defect is crucial to prevent impairment of masticatory function, loss of speech, cosmetic deformity and to essentially maintain the patient's quality of life. Certainly, the titanium plate with autogenous bone transplantation can be regarded as the primary standard and a reliable treatment for mandibular reconstruction [6]. In spite of the availability of reconstruction techniques related to autogenous 
bone graft, perfect mandibular reconstruction is still not possible and remains a challenge. Generally, the available standard commercial reconstruction plates (implants) are employed in mandibular reformation. These plates are manufactured using traditional methods such as casting and the powder metallurgical process, which are time consuming processes [7]. Furthermore, the standard plates are straight and they need bending in order to align them along the mandible curved bone. This not only raises the operative (or surgery) time, but also involves the tedious task of repeatedly adapting and revising the plate according to the patient's anatomy. Since, it is a trial and error procedure, the possibility of discrepancies between the bone and plate interface increases, which in turn causes implant failure as well as discomfort to the patient. Therefore, it is indispensable to utilize custom made implants, which not only reduce disproportion and mismatch, but also result in improved appearance and actualization. The personalized implant design not only enhances fitting accuracy, but also minimizes the surgical time in contrast to standard plates.

Recent developments in tissue and scaffold engineering represents a contemporary prospect and a new application in the evolution of mandibular restoration. Scaffolds can be combined with solid parts and fabricated as an implant. Ideally, the scaffolds should be highly porous, crack free and biocompatible with tissue ingrowth [8]. As reported by numerous clinical studies, the titanium scaffold (porous structure) can achieve long term bone fixation and promote full bone ingrowth when compared to the solid or bulk part $[9,10]$. In addition, solid titanium implants due to variation in mechanical properties as compared to bone may lead to bone resorption, which induces stress shielding effect on its surrounding bone and eventually leads to implant failure [11]. The impeccable porosity influences cell behavior and the interconnected channels of pores stimulate the vascularization [12]. The encouragement of early osseointegration is critically important for the success of implantation, otherwise longer healing time would lead to implant failure [13].

With advancements in engineering technology, including medical modeling software and three-dimensional (3D) printing or additive manufacturing, it is now possible to design and fabricate customized implants with better accuracy and in a shorter period of time. The unification of data acquisition, image processing, as well as modeling and additive manufacturing, have made it possible to comprehend tailor-made implants according to the patient's requirements. Undoubtedly, the implementation of integrated techniques can save a lot of money for medical practitioners as well as revamp the quality of life for a large number of people [14]. The agreeable effect in mandible restoration depends on many aspects of the implant, including its design, fabrication technology, biomechanical properties, accuracy, surface integrity and weight. Certainly, 3D printing techniques have emerged as a promising potential in the development of bone reconstruction, rehabilitation and in the field of surgery [15]. Among several 3D printing techniques, electron beam melting (EBM) has been regarded as the fast and successful method for the fabrication of titanium medical implants from computer-aided design (CAD) models with Food and Drug Administration (FDA) and Conformité Européene (CE) approval [16]. EBM technique, which was first commercialized in 1997 by ARCAM $\mathrm{AB}$, fabricate parts by melting metal powder in a layer-by-layer fashion [17]. It has increasingly been used for the fabrication of 3D titanium alloy scaffolds for medical applications with complex architecture $[18,19]$. Mandibular bone is not a uniform and regular structure, but rather a curved and special structure. Therefore, very few researchers have attempted to custom design prosthesis for mandibular reconstruction $[20,21]$ and very limited information is available on the study of mandibular scaffold. In addition, no clear evidence and investigation are available in the biomechanical, structural integrity and fitting evaluation of mandibular prosthetic scaffolds.

In this study, two different types of custom specific mandibular prosthesis scaffolds have been designed, fabricated and evaluated for their performance. These two designs were categorized as top and bottom porous plate and inner porous plate. In the top and bottom porous plate design, the mesh or porous structure was attached on the top and bottom of the plate, whereas in the inner porous plate design, the porous structure was inside the plate. An extensive integrated methodology has been utilized for the realization of the patient-specific porous implant. The part fabrication using EBM was 
supplemented with computer tomography (CT) for image acquisition and processing software for implant modeling. The two scaffold designs were also analyzed to determine their biomechanical effect under the mastication process using Finite Element Analysis (FEA), surface integrity using micro-CT scans as well as fitting accuracy and appearance utilizing the 3D comparison technique.

\section{Methodology}

The typical flowchart as shown in Figure 1, demonstrates the methodology adopted in this work. It was based on six primary steps: Data acquisition, customized implant design and modeling, virtual assembly, FEA, part fabrication and evaluation. This approach was prominent because it involved interaction between the engineering and medical fields right from the patient diagnosis until the mandibular reconstruction. The authors in this methodology have emphasized the importance of communication between the engineering and medical departments. In the current study, the medical practitioners were customers, therefore, they were engaged in each and every stage during the entire process. These communication links are evidently specified by using red circles in the Figure 1 . These communications acted as a feedback loop to get the assessment or the criticism from the medical people. Of course, the engineers had to explain various aspects and engineering terms or analysis to medical professionals before every session. This communication or information exchange helped to improve the overall results by minimizing design revision and preventing implant failure.

\subsection{Data Acquisition}

A forty-year-old patient with deformities and a lesion in the left mandibular area attended the emergency department of the university hospital. Upon diagnosis and a series of tests by the medical doctor, the patient was subjected to a non-invasive CT scans. The non-invasive CT can be defined as a medical procedure which does not involve any deterioration of the skin, internal body as well as the destruction of healthy tissues. During the course of patient diagnosis, it was found that the patient was suffering from mandibular continuity defect with a loss of portion of the bone resulting in a gap of $\sim 2 \mathrm{~cm}$ or more. It is a patient-specific defect which is larger in size. The CT images were acquired using a Promax 3D "Cone beam computer tomography machine" (Planmeca, Helsinki, Finland) [22]. The minimum resolution model (voxel size) was $0.10 \mathrm{~mm}^{3}$. It was implemented under the following conditions: Voltage-54-90 kV, Current-1-14 mA, Focal spot $0.4 \mathrm{~mm}$, detector resolution $127 \mu \mathrm{m}$, scan time 18-26 s. The radiologist performed the CT scan on the patient and saved the scanned images in Digital Imaging and Communications in Medicine (DICOM) format which is a universal stored format for medical images. The DICOM files containing a series of two-dimensional (2D) images, stored in a database, did not provide a perfect picture of the anatomical structure. Several medical modeling and image processing software available in the market were used to convert the 2D images into a 3D anatomical model. MIMICS 17.0 ${ }^{\circledR}$ (Materialise Interactive Medical Image Control System; Materialise NV, Leuven, Belgium) was used in this study. The 2D images of DICOM files were imported into MIMICS ${ }^{\circledR}$ which stacked the 2D images over each other and developed a typical 3D model. In medical CT imaging, the Hounsfield unit (HU) represents the grayscale from black to white with a range from -1024 (minimum value) to 3071 (maximum value). A custom thresholding Hounsfield unit of 282 to $2890 \mathrm{HU}$ was used for bone identification. Segmentation by thresholding technique was used to select the soft and hard tissue by defining the range of the threshold value. Figure 2 illustrates the patient mandibular tumor in a different view. 


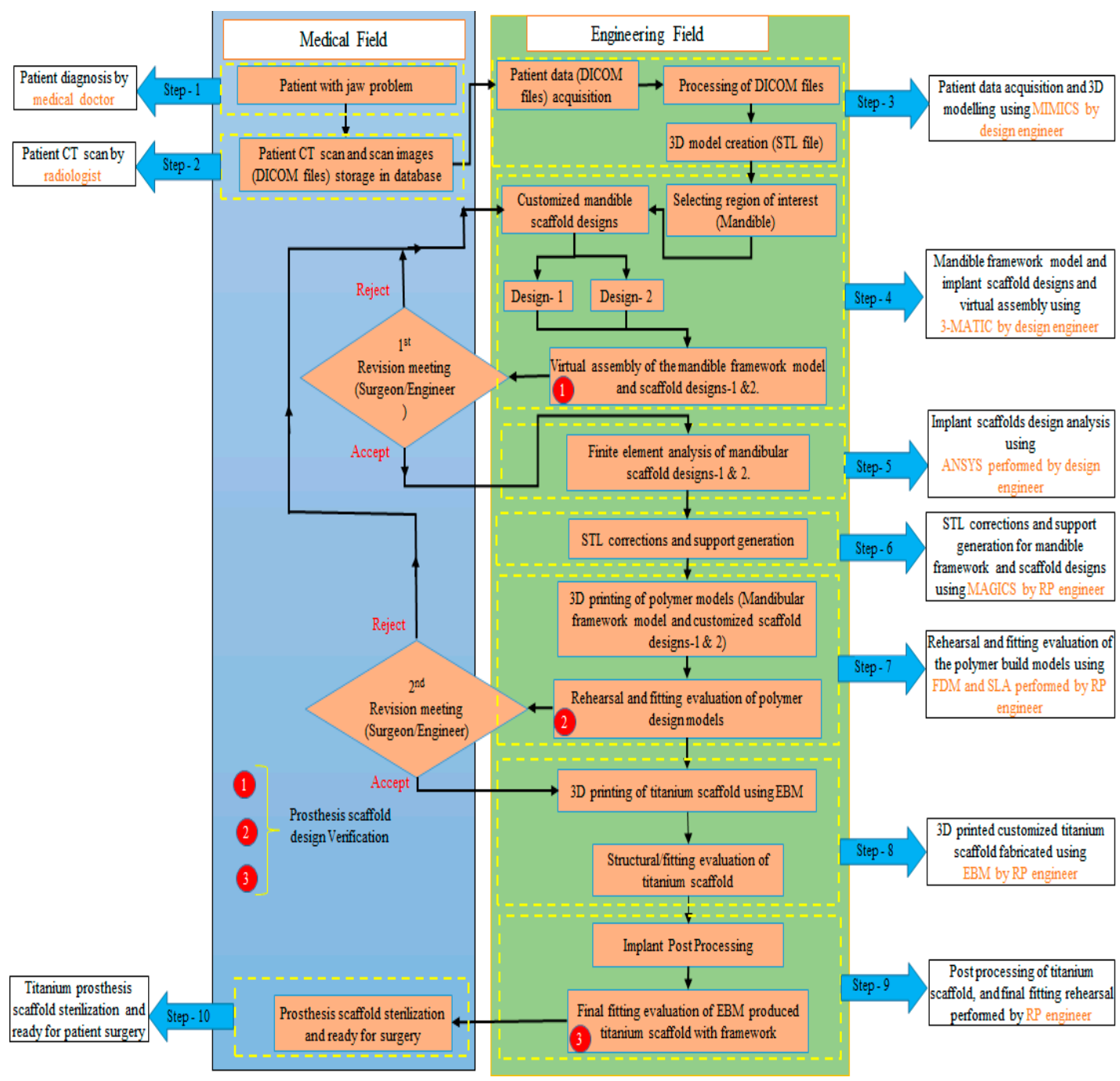

Figure 1. The proposed methodology for design, analysis and fabrication of customized mandibular prosthesis scaffolds. Note: The red circles indicate the formal meetings between the engineering and medical department for scaffold design verification and evaluation.

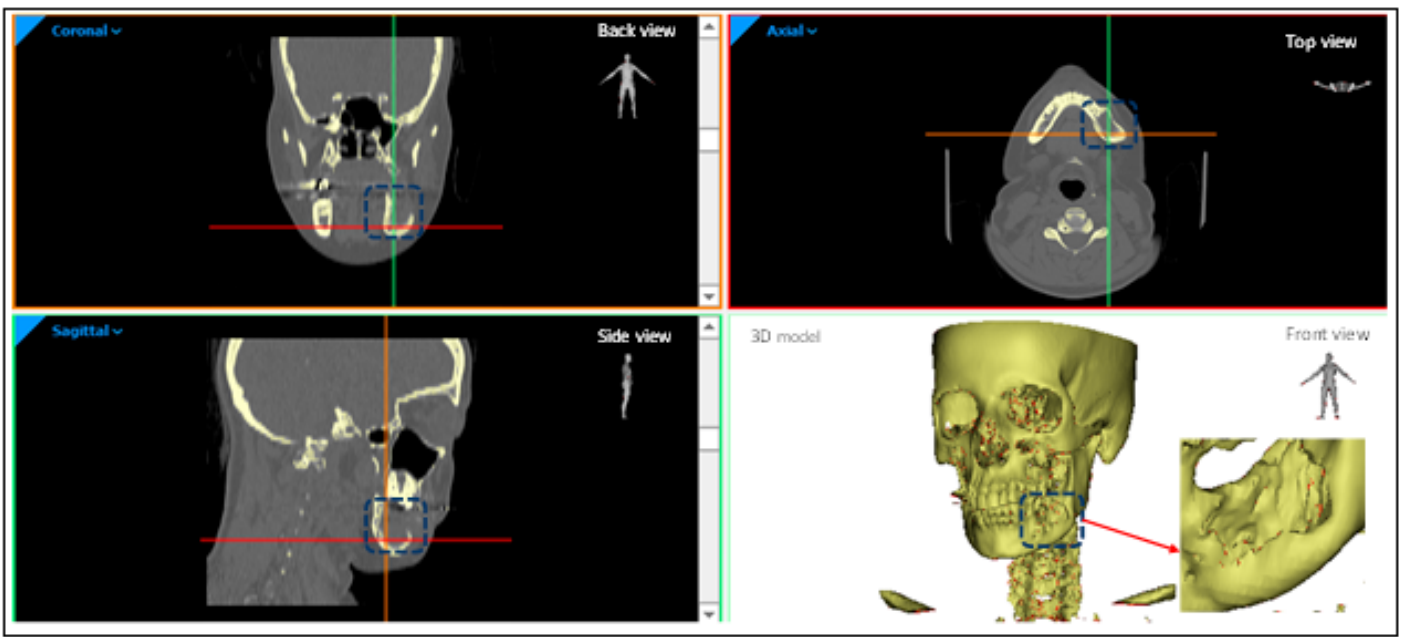

Figure 2. Patient anatomical model depicting the tumor region in different planes. 


\subsection{Customized Implant Design and Modeling}

The region growing technique using MIMICS was used to extract the region of interest (mandible) from the surrounding tissues. Figure 3a-e illustrates the region growing techniques, where the full face mask was segregated to the region of interest in mandible Figure 3e. The obtained tumor mandible without teeth was then saved as a Standard Tessellation Language (STL) file. The STL file was imported into 3-Matic ${ }^{\circledR}$ (Materialise, Leuven, Belgium) for implant design. Mirror reconstruction design technique is the most common implant design where the healthy bone is mirrored and replaced over the defective bone. Several research studies have proved that mirror reconstruction technique has successfully restored and provided excellent facial symmetry $[23,24]$. The tumor on the left mandible (Figure 3f) was resected and the right side of the healthy mandibular bone was mirrored as shown in Figure 3g. The symmetrical sides were merged to form a healthy mandible. Wrapping operation was performed to nullify the gaps and voids. The obtained healthy mandible (Figure 3h) was used for the implant design by selecting (Figure 3i) and extracting the outer region (Figure 3j) for customized implant design. Smoothing and trimming operations were performed to get the implant design shape as shown in Figure 3k. An offset thickness of $2 \mathrm{~mm}$ (Figure 31) was provided and two implant designs with one inner bone graft carrier and the other with top and bottom bone graft carrier were designed as shown in Figure $3 \mathrm{~m}, \mathrm{~m}^{\prime}$. The inner plate and thick top and bottom plate were patterned into the porous structure (scaffold) using dode thick (Figure 3n) from Magics ${ }^{\circledR}$ (Materialise, Belgium) as shown in Figure 3o. The dode thick mesh structure was used to reduce the weight of the mandibular implant and to provide good adhesion between the bone and the implant. Several research articles have proved that titanium scaffold with a porosity of 500-1000 microns influence the osseointegration and faster bone healing $[25,26]$. Figure $3 p$ illustrates the designed scaffold pore (900 microns) and strut (300 microns) size.

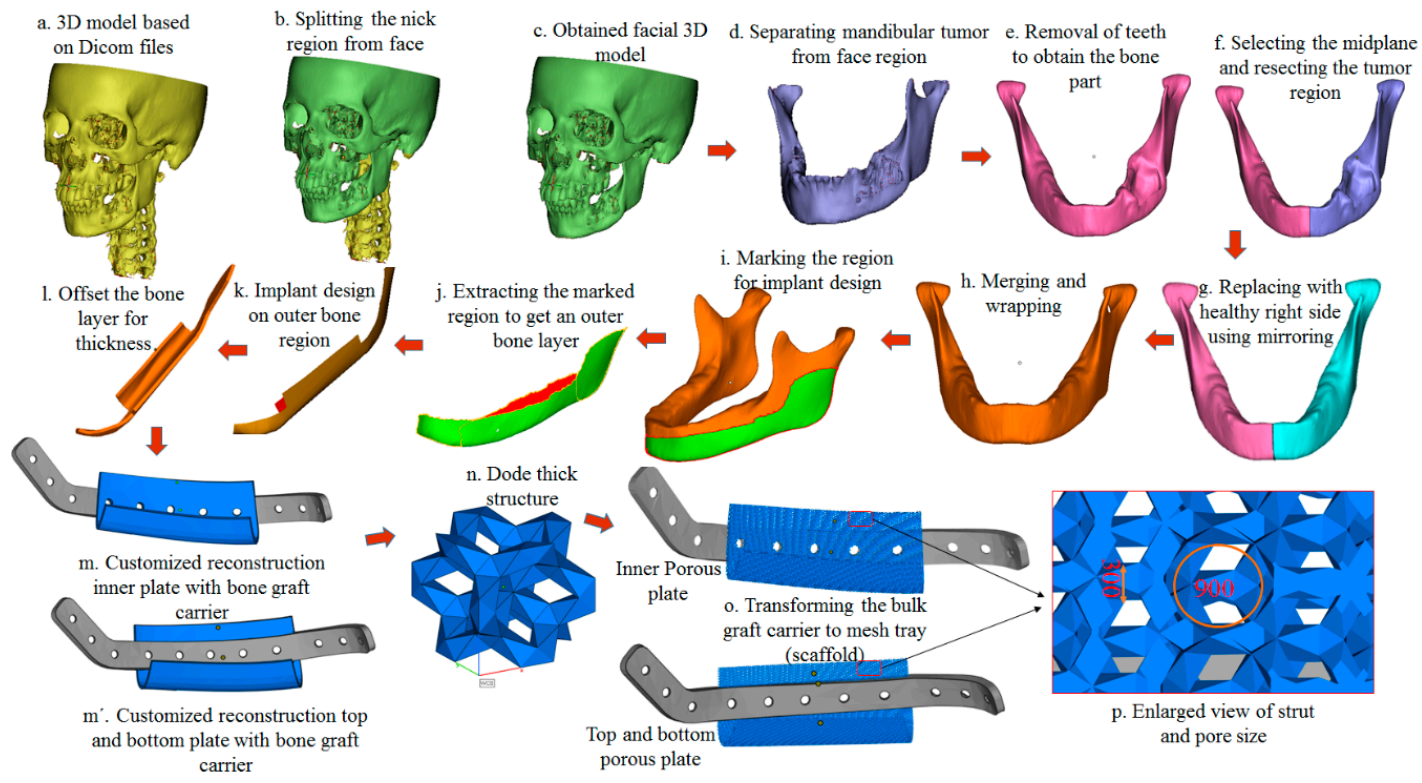

Figure 3. Sequence of steps in the design of customized prosthesis scaffold (implant) for mandibular defects.

\subsection{Virtual Assembly}

The two designed prosthesis scaffolds were virtually assembled and aligned with the mandibular framework model for fitting and assembly evaluation as shown in Figure 4. Formal meetings used to take place between the engineering and medical field for evaluating and verifying the design as indicated by red circles (Figure 1). Any error or void in-between the implant and the bone would result in the redesigning of the implant. The virtual assembly also helped with surgical guidance, 
understanding the surgical anatomy and real world preoperative surgery scenario to improve the reliability and safety of the surgical process.

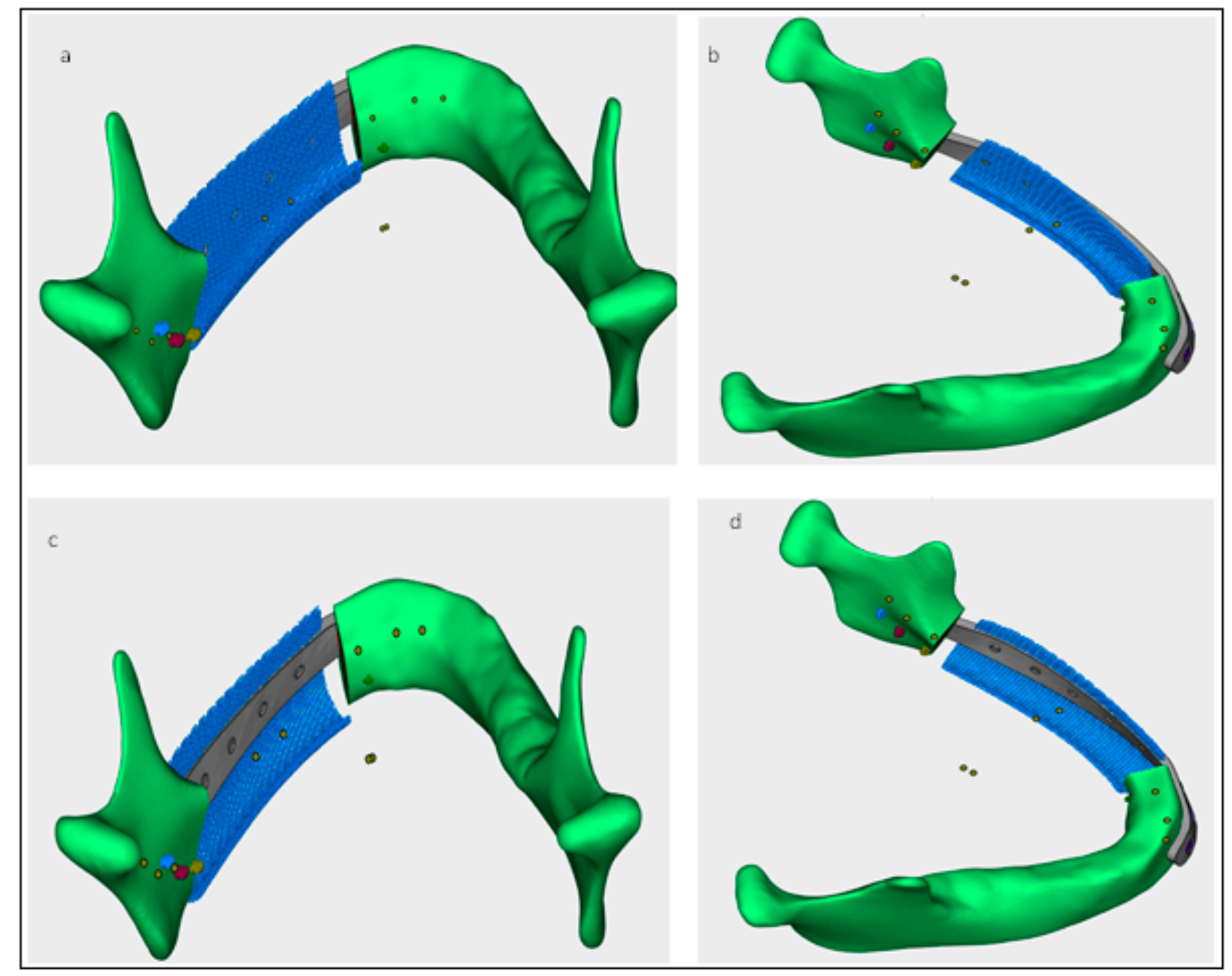

Figure 4. Posterior (back) and top view of the two customized scaffolds: Inner porous plate (a,b) and $(\mathbf{c}, \mathbf{d})$ top and bottom porous plate.

The designed reconstruction scaffolds were incorporated with countersink medical screw holes with three screws on the condyle side and three screws on the chin area. The countersink holes were designed for the complete immersion of the screw head inside the screw hole in order to provide a better aesthetic effect. Figure 5 illustrates the virtual assembly of the mandibular framework model containing the cortical and trabecular bone with scaffold fitted with six screws. The error free designed scaffold and the framework model were saved as a Standard for the Exchange of Product model data (STP) file for analysis.

\subsection{Finite Element Analysis}

Once the designed scaffolds were examined for fitting and conformance in the virtual assembly, the FEA model was created to evaluate their functionality as well as the biomechanical effect of clenching on the prosthesis scaffold. The FEA was employed because it is recognized as one of the crucial tools to emulate and predict the behavior of the CAD model in real scenarios. It was first used in the aerospace industry but quickly spread throughout a wide range of sciences including medicine and dentistry [27]. A finite element model (FEM) consisting of the temporomandibular model and two designed scaffolds was created using Ansys ${ }^{\circledR}$ software. In this study, the sustained clenching and masticatory muscle activity using three muscular forces (masseter, medial pterygoid and temporalis) were simulated. The material properties of the cortical bone, trabecular bone, screws and scaffold were adapted from the literature study and were assumed as homogeneous, isotropic and linear elastic [28,29]. The Young's modulus, Poisson's ratio and yield strength of the simulated study are presented in Table 1. 


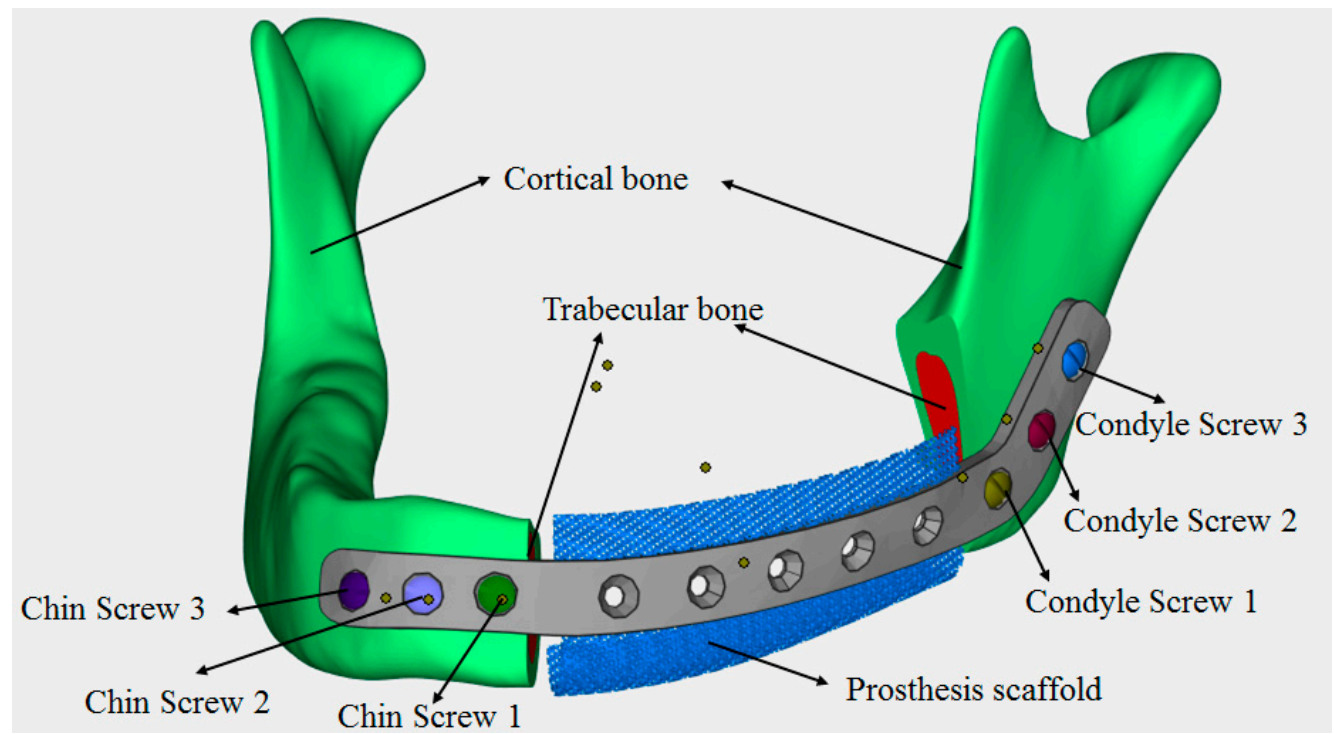

Figure 5. Global view of virtual design assembly of customized prosthesis scaffold on the mandibular framework model.

Table 1. Mechanical properties of study materials used in FE model. Data from [28,29].

\begin{tabular}{cccc}
\hline Materials & Young's Modulus (MPa) & Poisson's Ratio & Yield Strength (MPa) \\
\hline Compact Bone & 13,700 & 0.3 & 122 \\
Trabecular Bone & 1370 & 0.3 & 2 \\
Prosthesis scaffold, (Ti6Al4V ELI) & 120,000 & 0.3 & 930 \\
\hline
\end{tabular}

For clenching simulation, the superior part of both condyles was constrained in all directions. The displacement in the molar region as shown in Figure 6 was restrained in the upper region to simulate chewing. While the biting forces acted axially, the molar movement was kept at near zero displacement. This restraint was perpendicular to the occlusal plane (Z-direction), while allowing freedom of movement in the horizontal plane ( $X$ and $Y$ direction). The FEM was meshed with the 10-node 3D tetrahedral element.

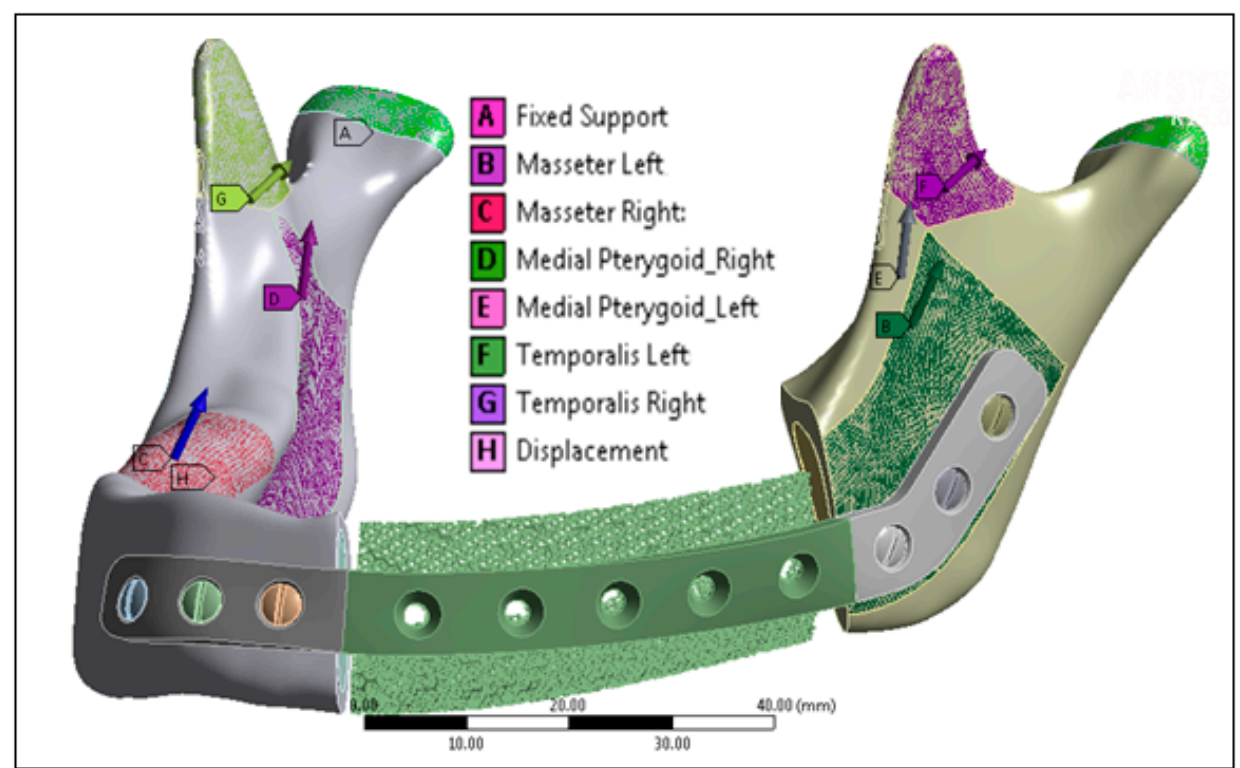

Figure 6. Typical loading and boundary constraints on mandibular framework model with prosthesis scaffold. 
As shown in Figure 7, the triangle surface mesher strategy with program controlled patch conforming method was used in order to refine the mesh at the area of fixation and to obtain more accurate results. The magnitude and boundary condition of the masticatory forces were derived from the literature study $[30,31]$. The interface between the scaffold-bone and screw-scaffold-bone were considered as bonded. The clenching movement was simulated in the FEM with muscular forces and their vectors are presented in Table 2.

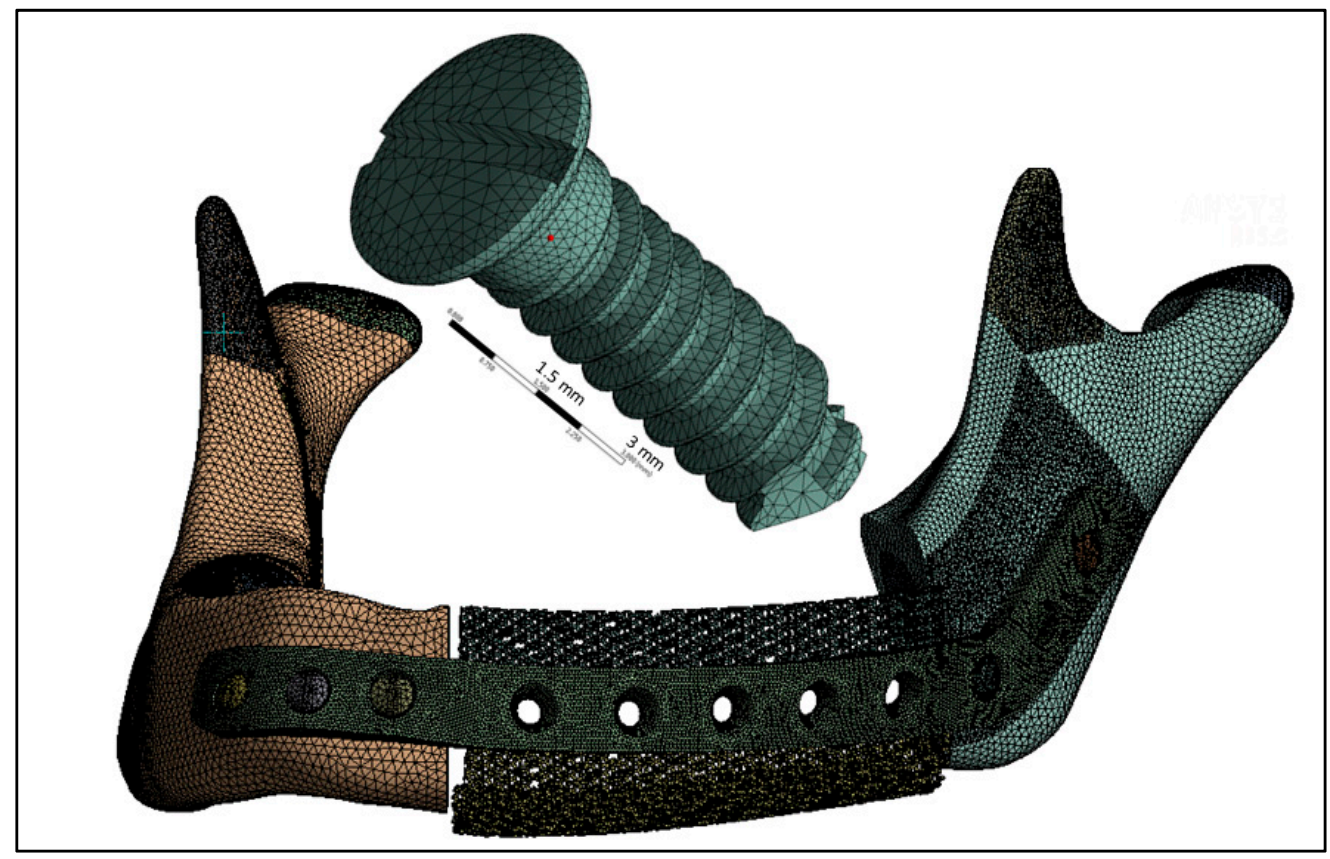

Figure 7. Meshing on the simulated mandibular framework model with prosthesis scaffold and a close-up view of screw meshing.

Table 2. Magnitude and functional direction of masticatory muscles in Newton's (N). Data from [30,31].

\begin{tabular}{cccc}
\hline Masticatory Muscles & $\mathbf{X}(\mathbf{N})$ & $\mathbf{Y}(\mathbf{N})$ & $\mathbf{Z}(\mathbf{N})$ \\
\hline Masseter & 50 & -50 & 200 \\
Medial pterygoid & 0 & -50 & 100 \\
Temporalis & 0 & 100 & 200 \\
\hline
\end{tabular}

\subsection{Fabrication}

In this study, 3D printing was used for the fabrication of customized prosthesis scaffolds. Two types of materials-polymer and metal-were used in the fabrication. The polymer 3D printing was used for the testing and fitting evaluation (virtual assembly), whereas metal (Ti6Al4V ELI) was used for the patient prosthesis implant. For polymer-based 3D printing, Stratasys-fused deposition modeling (FDM) machine and FORMLABS-2 a (stereolithography) SLA machine were used. ARCAM's EBM machine (EBM A2, ARCAM AB, Mölndal, Sweden) was used for printing titanium metal scaffolds.

\subsubsection{Polymer Fabrication}

The FDM machine as shown in Figure 8a was used to print mandibular framework models (Figure 8b) using ABS (acrylonitrile butadiene styrene) material which is a common thermoplastic resin with good functional properties [32]. FDM works on additive manufacturing process where the ABS material unwound from the coil and is heated to melting point and extruded in a layer-by-layer fashion to produce 3D objects. Formlabs-2 3D printer as shown in Figure 8c was used to fabricate the mandibular prosthesis scaffold (Figure $8 \mathrm{~d}$ ) which used the liquid resin material. Formlabs-2 
form works on laser-based SLA principle where the laser solidifies the liquid resin material in a photo-polymerization process and builds the 3D model in a layer-by-layer fashion [33]. SLA produces objects with higher resolution with more accuracy when compared to FDM due to its optimal spot size laser which is very small [34]. Formlabs-2 was used in the fabrication of mandibular scaffold as it provided higher resolution and accuracy for the complicated porous structures.

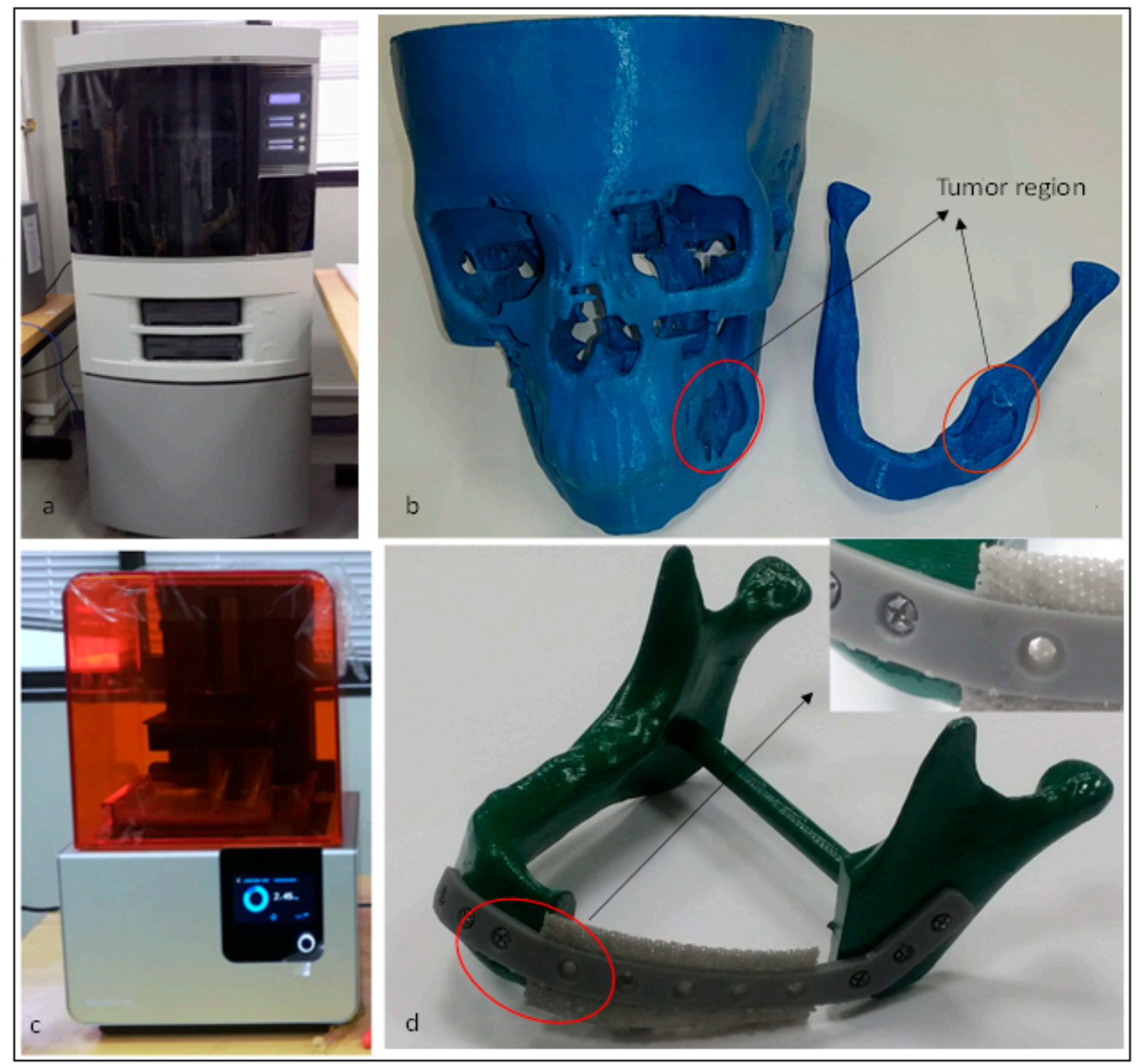

Figure 8. (a) Fused Deposition Modeling machine with its fabricated polymer model (b) indicating the tumor region and (c) SLA machine and its produced mandibular scaffold (d) with a close-up view.

\subsubsection{Titanium Fabrication}

It is well proven that scaffolds with elastic modulus closer to that of bone, minimizes the stress shielding effect and promotes bone-implant tissue in-growth [35,36]. Powder bed metal based 3D printing technologies such as EBM and selective laser melting (SLM) have demonstrated the capability to produce scaffolds in medical applications [37]. The EBM process in comparison requires less supporting material and minimizes post processing steps such as machining and heat treatment [36]. An EBM process is most suited for reactive metals such as titanium alloy as the complete build process takes place in a vacuum environment [38]. In addition, EBM produces parts at a much faster rate (80 $\left.\mathrm{cm}^{3} / \mathrm{h}\right)$ when compared to SLM $\left(20-40 \mathrm{~cm}^{3} / \mathrm{h}\right)$ [39]. The standard layer thickness of the printed samples using ARCAM's A2 EBM machine was 50-70 $\mu \mathrm{m}$.

Figure 9a,b illustrates the typical working principle of the EBM process and the different components of the EBM machine respectively. The tungsten filament in the electron beam gun on 
reaching above $2500{ }^{\circ} \mathrm{C}$, emits a beam of electrons which accelerates at half the speed of light and passes through a series of controlled coils (lens) and impacts the powder surface, thus melting the powder. The first (astigmatism) lens assists to keep the beam in circular and round shape regardless of its position on the build plate. Without this coil, the focus point of the beam tends to have a wider area (elliptical shape) when it is deflected towards the edge of the build region. It also eliminates electro-optical artifacts (human error). The second (focus) lens keeps the beam in focus and sharpens to a desired $(0.1 \mathrm{~mm})$ diameter. The third (deflection) lens scans the beam across the build area. The build process takes place inside the build chamber. Inside the build chamber, there are two hoppers which hold the metal stock powder. Metal powder is spread homogeneously over the build table using rakes. The rakes fetches the powder from either end of hoppers and spreads it evenly over the build table. The build tank lowers down in the z-direction after each melt cycle. The start plate was placed at the center of the build table which holds the build surrounded by powder. Vacuum is maintained throughout the build cycle to eliminate impurities and to prevent reactions between the reactive metals. Titanium powder (Ti6Al4V ELI) with the particle size of 50-100 mm was used in this study. The chemical composition of Ti6Al4V ELI (extra low interstitial) was made of $6.04 \% \mathrm{Al}, 4.05 \% \mathrm{~V}$, $0.013 \% \mathrm{C}, 0.0107 \% \mathrm{Fe}$, and $0.13 \% \mathrm{O}$, while the rest as Titanium (in weight percent).

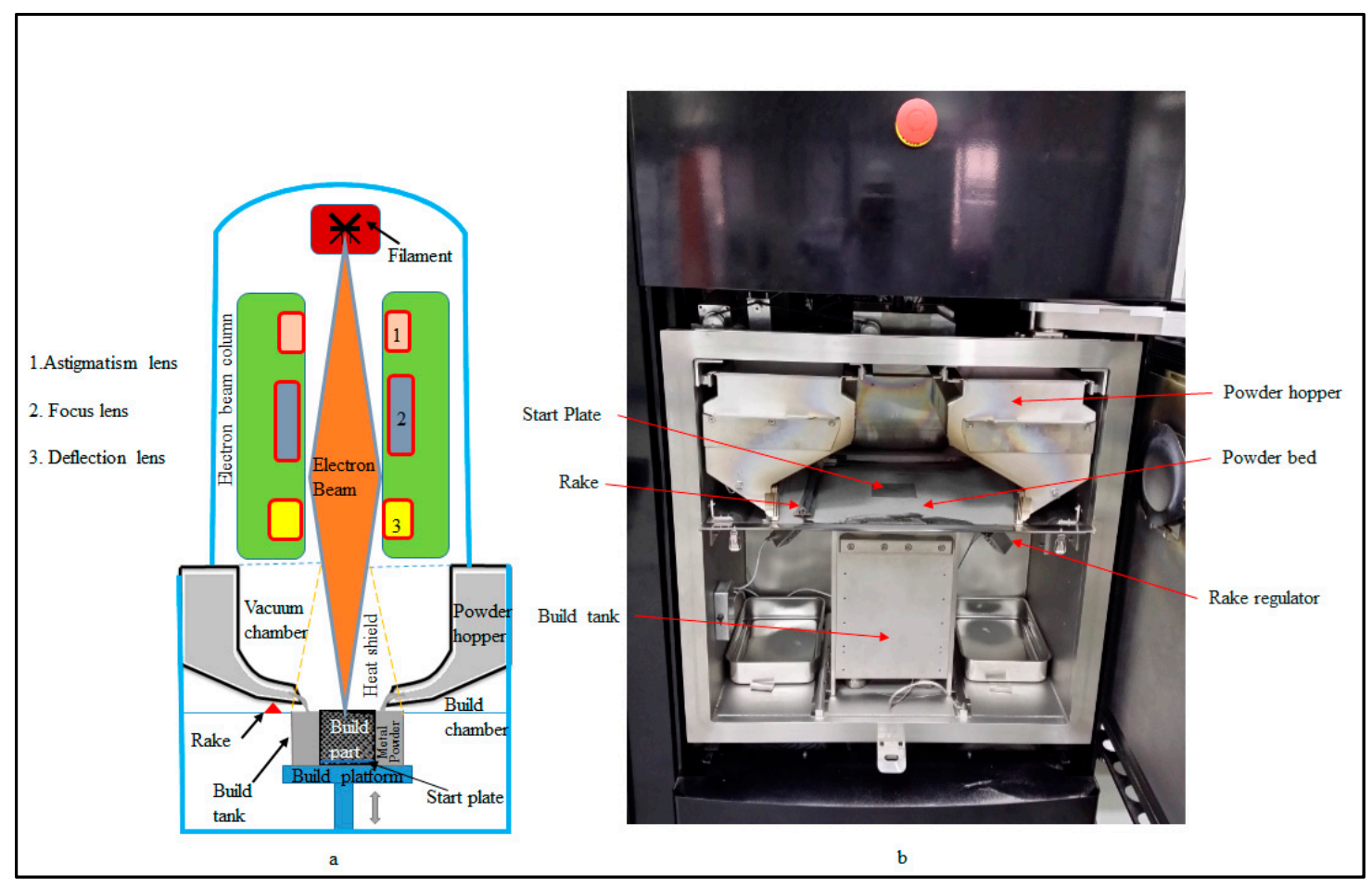

Figure 9. (a) Schematic representation of the EBM process and (b) EBM build chamber with part details.

The part fabrication in the EBM machine (ARCAM A2) as shown in Figure 10b is dependent on three phases-(1) Preheating of the metal powder. (2) Scanning and melting. (3) Lowering of build table and raking of powder.

(1). Preheating the metal powder: The Ti6Al4V ELI metal powder spread on the powder bed is preheated by multiple beams of electron at high scan speed and low beam current to reduce the internal residual stresses.

(2). Scanning and melting: The high velocity beam of electrons scans the metal powder and melts the power in line as per the defined CAD geometry. The melting process consist of two steps, melting the contours (outer and inner boundary) and infill hatching. The majority of the melting takes place in hatching where the beam current and scan speed are increased. 
(3). Lowering build table and raking of powder: The build table is lowered after each melt layer cycle $(50 \mu \mathrm{m})$ and a new layer of powder is fed from hoppers and spread evenly on the previously solidified powder layer using rakes. This process continues till the final 3D part is built.

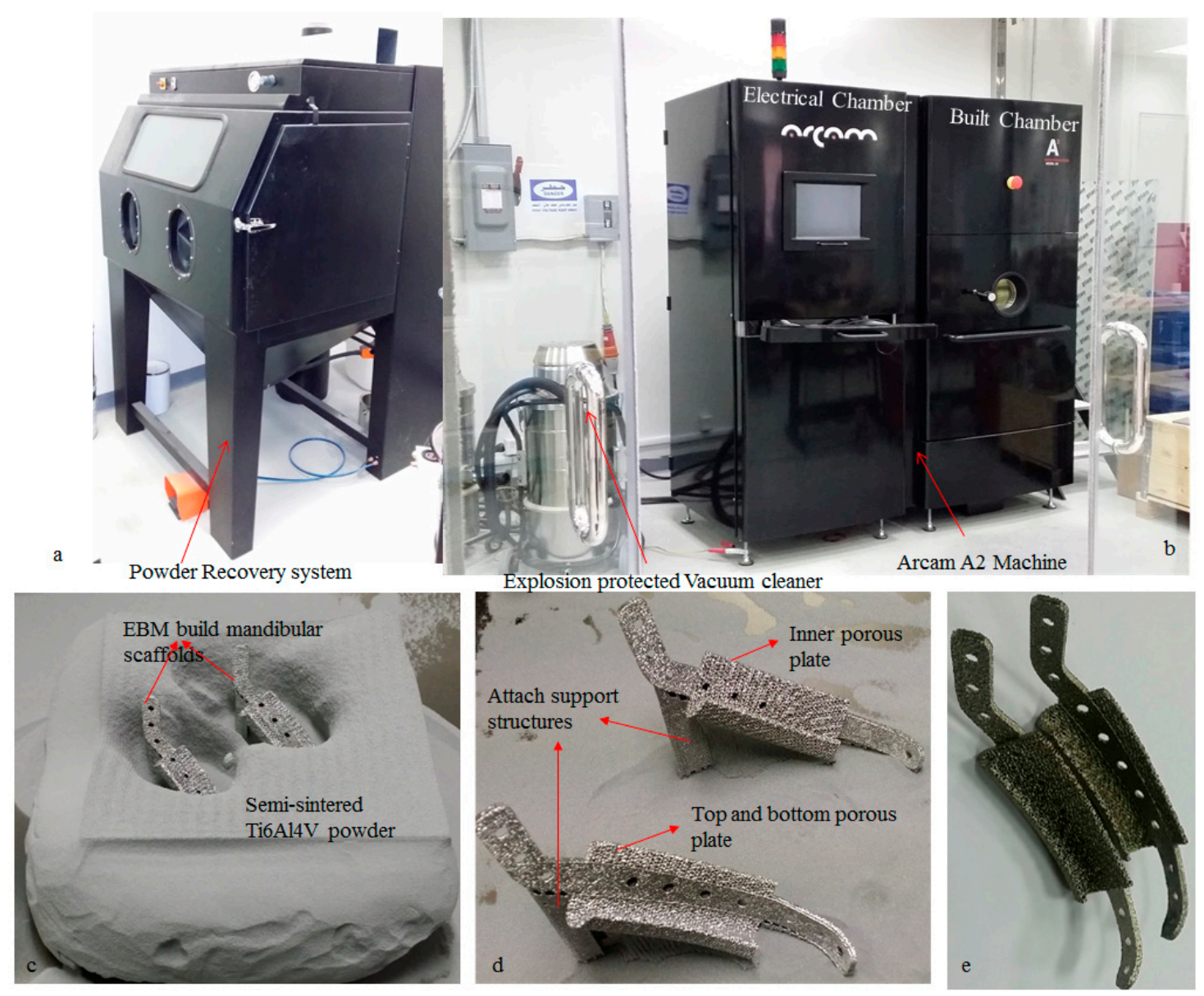

Figure 10. (a) PRS machine, (b) EBM machine with explosion protection vacuum cleaner, (c) EBM built mandibular prosthesis scaffold surrounded by semi-sintered powder, (d) titanium scaffolds with support structures and (e) mandibular scaffolds after support removal.

The EBM build lasted approximately 8-10 h. After build completion, the produced part (mandibular prosthesis scaffold) was allowed to cool under helium gas. Figure 10c shows the EBM build scaffold with supports surrounded by semi-sintered powder. The semi-sintered titanium powder was then blasted in powder recovery system (PRS) as shown in Figure 10a as a post processing process and to get the finished part with supports. The supports (Figure 10d) which were added to the scaffolds during the build to dissipate the heat and the overhang structures were manually removed with simple tools such as pliers. Figure 10e illustrates the final EBM built mandibular scaffolds which can be sandblasted or machined using laser ablation to achieve a smoother finish if required [40].

\subsection{Evaluation and Validation}

At this stage, the fabricated titanium scaffolds were investigated for structural integrity, fitting accuracy as well as the weight.

\subsubsection{Micro-CT Scan on Titanium Lattice Structure}

A non-destructive technique (i.e., micro-CT scan) was employed in order to examine the stochastic defects and structural integrity of the dode thick mesh structure used in scaffold design. The micro-CT 
scans were utilized in order to validate the quality of the dode thick structure in terms of cracks, internal trapped powder, in addition to examine the interior construction of the built struts without any physical cutting and polishing. A $15 \mathrm{~mm}$ solid cube (Figure 11a) was designed and transformed into a dode thick structure (Figure 11b,c) and fabricated using EBM as shown in Figure 11d. The micro-CT scanner (Bruker Skycam 1173, Kontich, Belgium) with a source voltage of $120 \mathrm{KV}$ focused on the EBM fabricated cube structure with a spot size of $5 \mu \mathrm{m}$ and with an image pixel size of $12.03 \mu \mathrm{m}$. Each 2D slice image of the cubic structure in the form of $512 \times 512$ bitmaps as output data was collected.

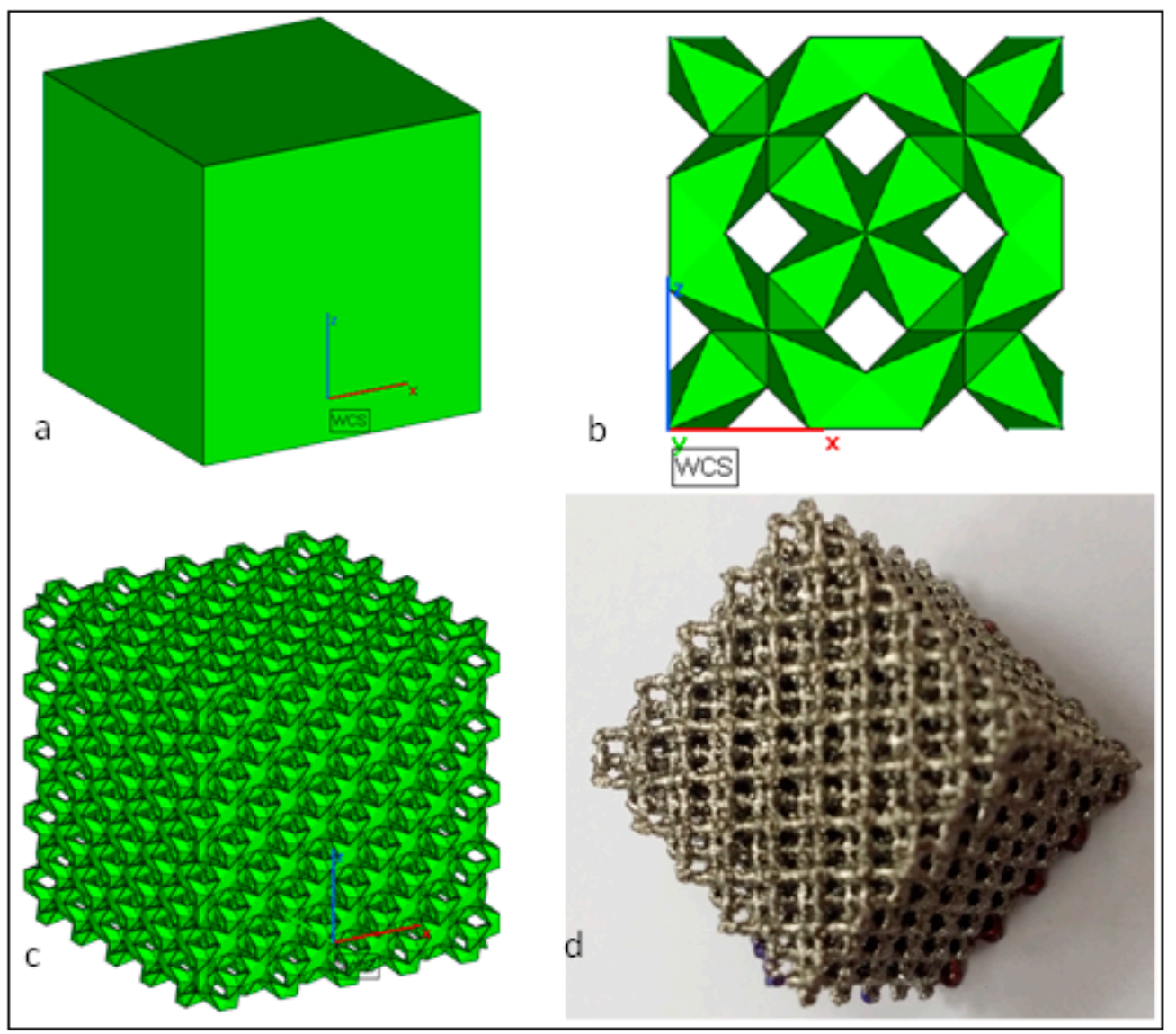

Figure 11. Cubes with unit cell structure of $15 \times 15 \mathrm{~mm}^{2}$ (a) solid cube, (b) dode thick unit cell structure, (c) dode thick cube structure and (d) EBM fabricated dode thick cube.

\subsubsection{D Comparison}

The 3D comparison technique was implemented in order to accurately compare the fitting accuracy of both the implant designs (inner porous plate and top and bottom porous plate) with respect to the mandible. The fitting accuracy of the implants was computed using Geomagics Control ${ }^{\circledR}$ [41]. The $3 \mathrm{D}$ comparison analysis can be considered as one of the most powerful and extensive techniques, to graphically represent the surface deviations between the reconstructed objects and the reference CAD model [42]. At the outset, the test model had to be aligned on the reference CAD model by utilizing the best fit alignment. Consequently, the analysis software automatically estimated the best fit between the test and reference object. This best fit alignment confirmed that both the test and reference objects were positioned (or fixed) in the same coordinate system. Furthermore, the statistic used in this work in order to quantify the fitting accuracy of the implants on the mandible was the average deviation. This statistic was utilized because it reported the deviation in the mandible, thereby approximating the gap between the implant (scaffold) and the mandible. In this work, the test model was acquired as a point cloud set by employing the laser scanner mounted on the Faro Platinum arm (FARO, Lake Mary, FL, USA) as shown in Figure 12. 


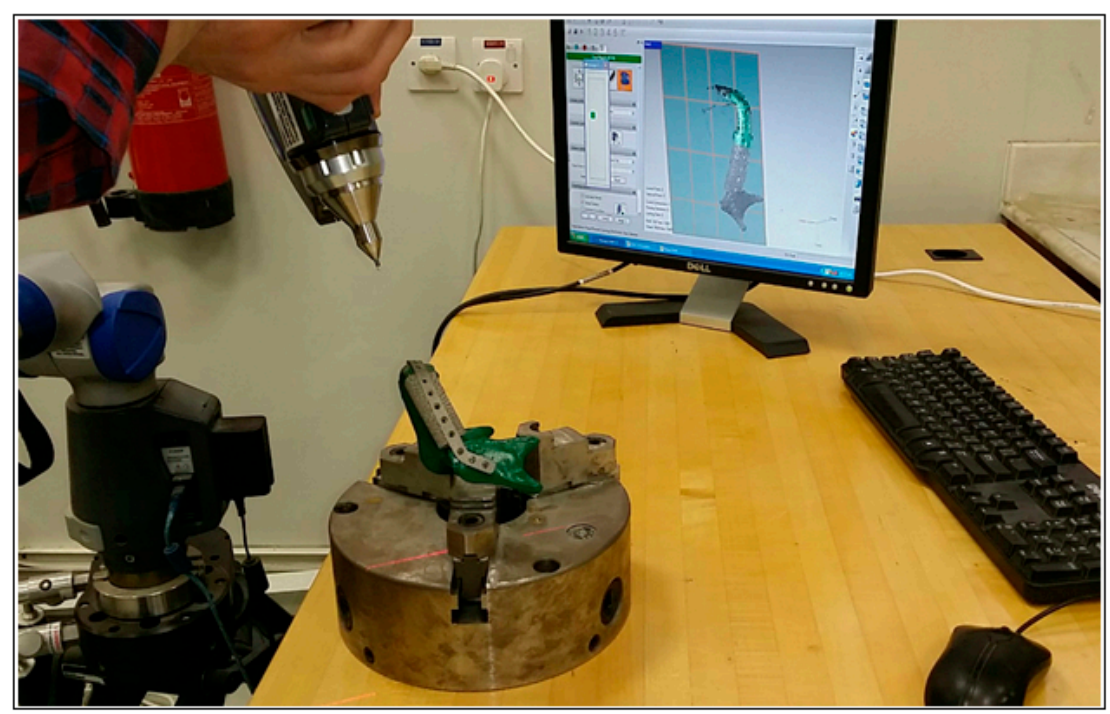

Figure 12. Acquisition of test data using a Faro Platinum arm.

As shown in Figure 13, the scaffolds were mounted on the mandible and scanned to obtain the test data. The reference model was obtained by removing the defect and imitating the healthy side on it. The reference model acquired using the mirroring technique was assumed to represent the ideal anatomical structure [23,24].
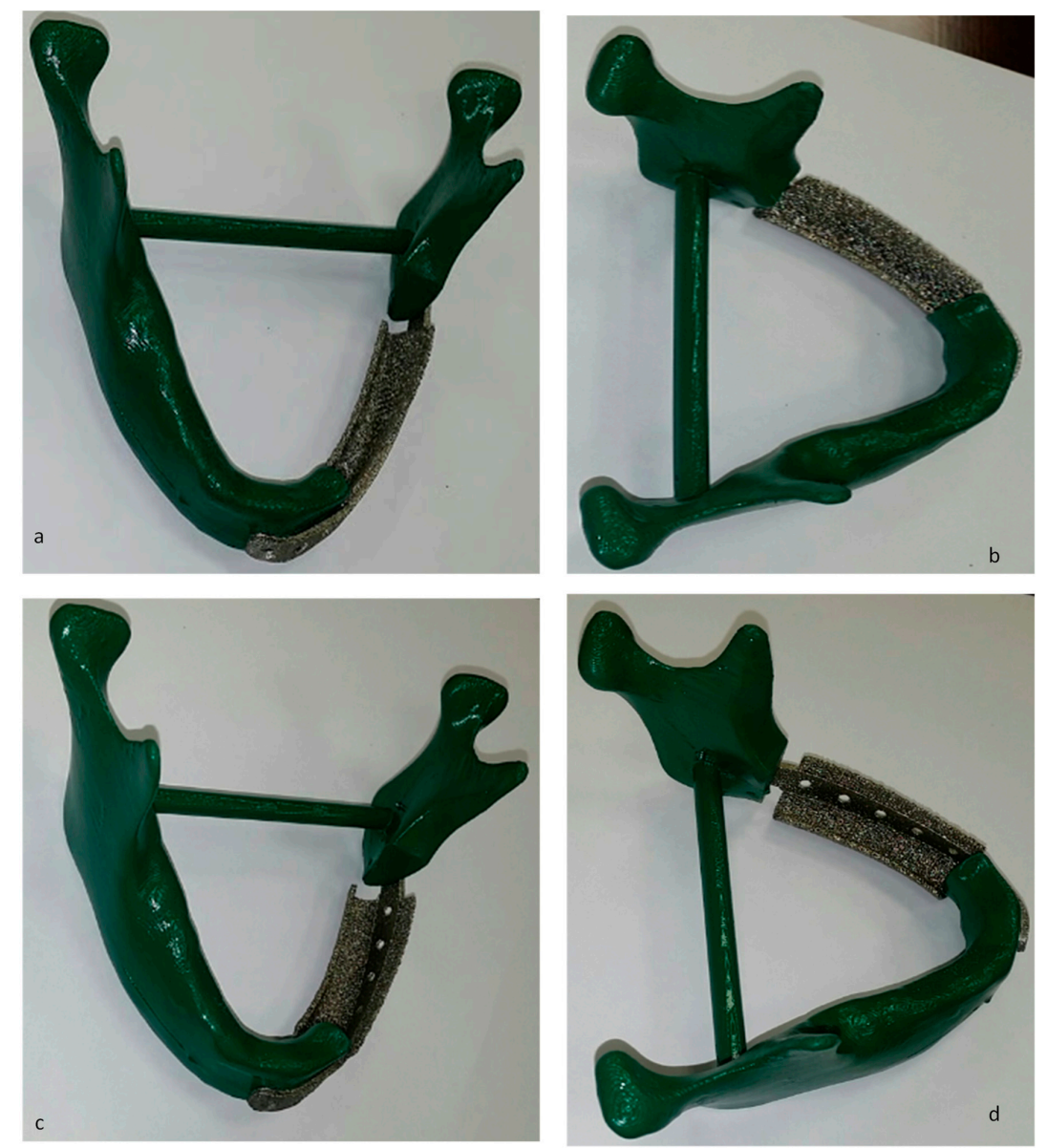

Figure 13. Mandible prosthesis scaffold $(\mathbf{a}, \mathbf{b})$ inner porous plate and $(\mathbf{c}, \mathbf{d})$ top and bottom porous plate mounted on the mandibular framework. 
The outer surface of the scaffold mounted mandible were scanned and imported as STL model in Geomagics control ${ }^{\circledR}$ in order to compare it with the reference mandible. The outer surface was studied because the customized scaffolds were designed depending on the outer profile of the mandible. The 3D comparison analysis software represented the result by means of error scale through the computation of the shortest distance between the test model and the surface of the reference model.

\subsubsection{Weights of the Scaffold Designs}

In order to reduce the stress shielding effect between the implant and the surrounding bone, it was imperative to build lighter implants with weights closer to that of the bone being replaced [43]. The minimization of stress shielding was critical for reducing bone resorption as well as decreasing the rate of aseptic loosening. The weight of the mandibular bone to be replaced was calculated from the density formulae where volume was taken from the Magics ${ }^{\circledR}$ software (Materialise, Leuven, Belgium) and assuming density as $1600 \mathrm{~kg} / \mathrm{m}^{3}$ [44]. The weights of the two EBM fabricated scaffolds were measured using a digital weighing machine.

\section{Results and Discussion}

In this work, two customized prosthesis scaffolds were designed from the patient CT scan files. The clinical setup for both the designed scaffolds were simulated under physiological clenching conditions. The FEA analysis was essential in order to find out the continuous grabbing and chewing ability of the designed customized implants. The equivalent stresses and strains observed on both scaffolds are presented in Figure 14. The results indicated that the maximum stresses in both customized scaffolds were confined to the mesh structure and it was evident due to its lower cross sectional area.

The simulated result summary of both designed scaffolds is presented in Table 3 . The analysis showed that the FEA of inner porous plate design induced higher stress concentration than the FEA of top and bottom porous plate design. In addition, the maximum stresses on both the prosthesis scaffolds were well below the yield strength $(930 \mathrm{MPa})$ of the titanium alloy (Ti6Al4V ELI). On further observation, the analysis results of the screws, revealed that the condyle screws exhibited higher stresses when compared to chin screws which indicated that the stresses were transferring from the bottom chin region towards the condyle side thus satisfying the mastication process [45].

Table 3. Summary of Von Mises stress, strain and deformation of two designed scaffolds.

\begin{tabular}{|c|c|c|c|c|c|c|c|c|c|}
\hline \multirow{2}{*}{\multicolumn{4}{|c|}{ FEA Outcomes }} & \multicolumn{3}{|c|}{ Stress on Chin Screw (MPa) } & \multicolumn{3}{|c|}{ Stress on Condyl Screw (MPa) } \\
\hline & & & & \multicolumn{6}{|c|}{ Screw Numbers } \\
\hline Designed Implant & $\begin{array}{c}\text { Max Von Mises } \\
\text { Stress (MPa) }\end{array}$ & $\begin{array}{c}\text { Max } \\
\text { Strain }\end{array}$ & Deformation & 1 & 2 & 3 & 1 & 2 & 3 \\
\hline Inner porous plate & 360.22 & 0.0032 & 0.29852 & 55.85 & 38.26 & 50.52 & 122.9 & 121.74 & 81.5 \\
\hline $\begin{array}{l}\text { Top \& bottom } \\
\text { porous plate }\end{array}$ & 214.77 & 0.0068 & 0.31711 & 61.85 & 39.76 & 53.61 & 127.71 & 125.07 & 84.44 \\
\hline
\end{tabular}

The most common cause for the failure of the mandibular reconstruction is either due to the reconstruction plate failure (excessive loads) or instability in the anchoring of the screws. In this study, the maximum stresses were found to be on the scaffold rather than on the screws and were well below the yield point and fatigue strength of the material. The stresses found on the screws in both the FEM were quiet less and within the failure limits, with the highest stress observed on the top and bottom screw plate. The other important parameter of the reconstruction plate design is its flexibility, to absorb the forces and chewing load conditions. The max strain on the inner porous plate was found to be 3.2 microns and the top and bottom porous plate was 6.8 microns. The maximum strain obtained on both the designed scaffolds was less and few microns. Based on the FEA results, it seems more reasonable to use prosthesis based on the top and bottom porous plate design for mandibular reconstruction, though both the plates were mechanically stable for fixation and could bear the masticatory functions. 


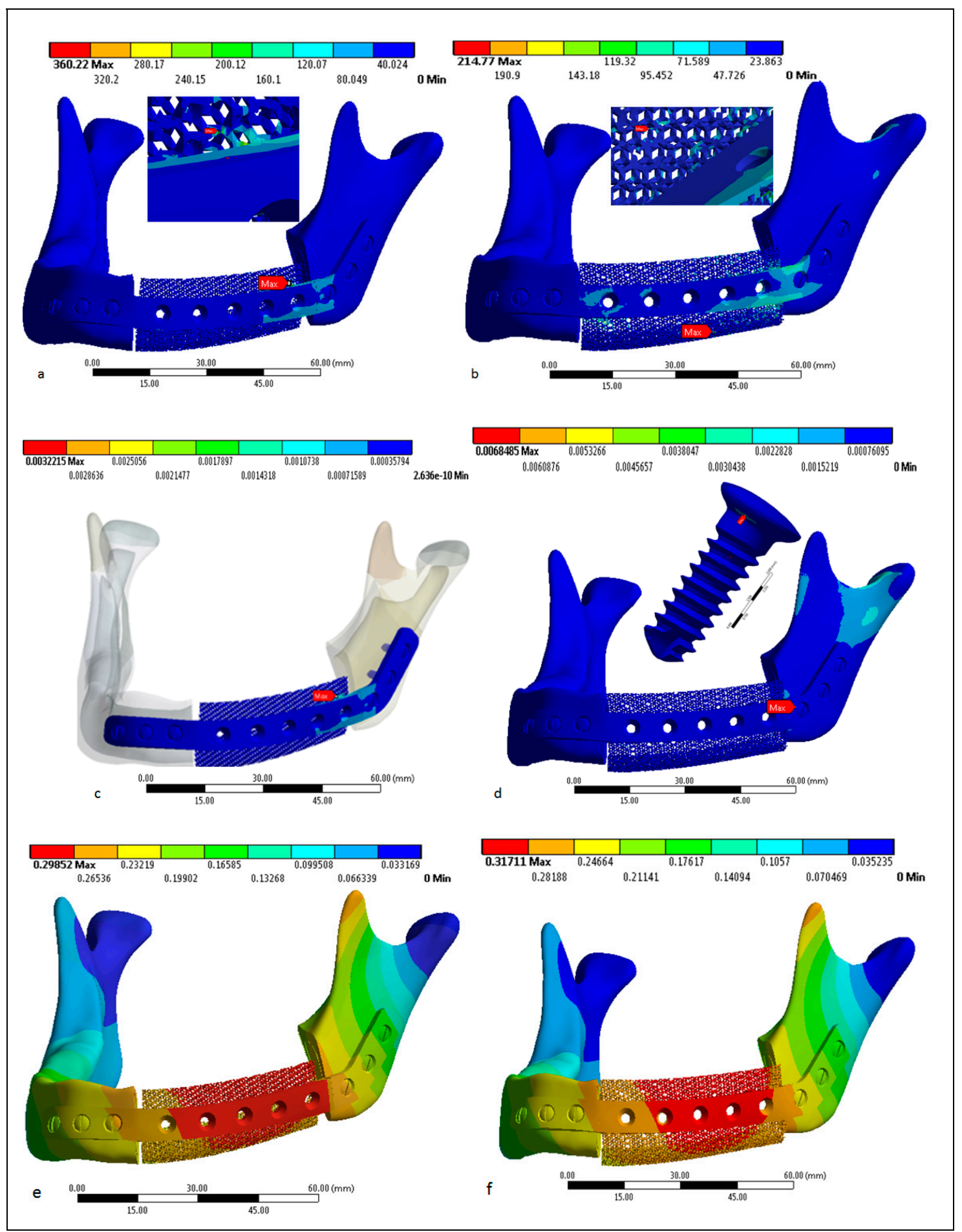

Figure 14. Von Mises stress (top), strain (middle) and deformation (bottom) distribution of mandibular framework model with two scaffolds $(\mathbf{a}, \mathbf{c}, \mathbf{e})$ inner porous and $(\mathbf{b}, \mathbf{d}, \mathbf{f})$ top and bottom porous plate.

The micro-CT scan results as shown in Figure 15 indicated that the dode thick structure was interconnected by a series of network channels and was free from any substantial internal defects such as cracks or voids. Similar results can be assumed and expected for the EBM fabricated mandibular prosthesis scaffold with dode thick structure. 


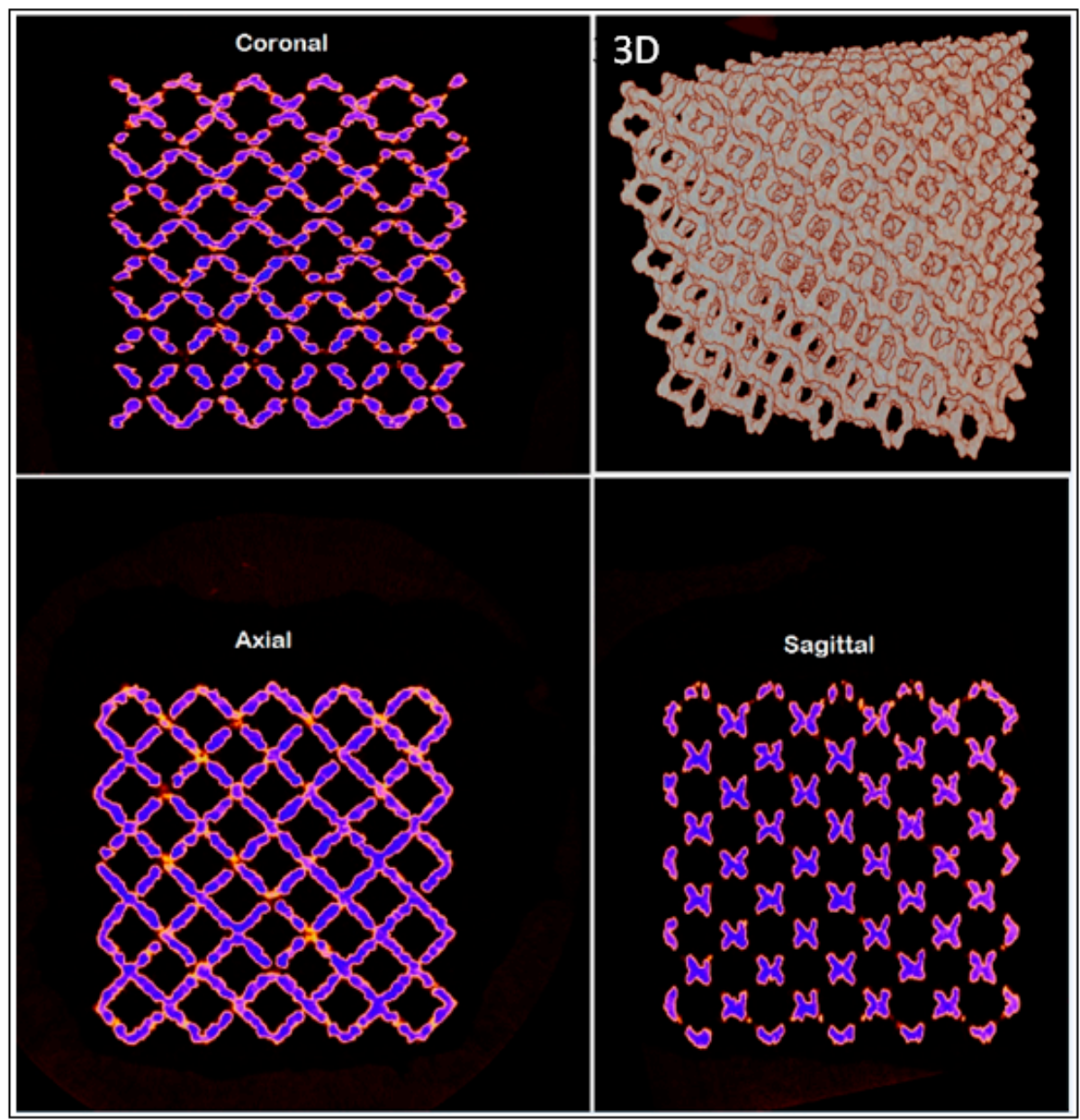

Figure 15. Micro-CT scanning of EBM fabricated dode thick cube representing different cross-sectional views.

The outcome of the 3D fitting deviation analysis has been represented graphically in Figure 16. The comprehensive investigation revealed that the scaffold with the top and bottom porous plate design provided better fitting accuracy as compared to the scaffold with inner porous plate design. An average deviation of $0.8274 \mathrm{~mm}$ was observed in the top and bottom porous plate design in comparison to $0.9283 \mathrm{~mm}$ of gap in the inner porous plate design.

The results of the weight analysis are presented in Table 4 . The weight of the inner porous plate design was found to be $10.67 \mathrm{~g}$ and the top and bottom porous plate was $8.14 \mathrm{~g}$. The weights of both reconstruction scaffolds were taken without considering the bone graft which will be placed inside the mesh carrier (tray) upon implant. Both scaffolds were low in weight and closer to that of bone properties. Certainly, this analysis confirmed that both the proposed designs possessed a lighter weight in comparison to their bone counterpart (19 g).

Table 4. Weight details of EBM fabricated scaffolds and replaced mandibular bone portion.

\begin{tabular}{cccc}
\hline Parts & Replaced Bone & Inner Porous & Top and Bottom Porous \\
\hline Volume $\left(\mathrm{mm}^{3}\right)$ & 11879.00 & 2016.00 & 1847.00 \\
\hline Weight $(\mathrm{g})$ & 19.00 & 10.67 & 8.14 \\
\hline
\end{tabular}

The Figure 17 illustrates the polymer and EBM fabricated titanium mandibular prosthesis scaffolds for final review before surgery. 


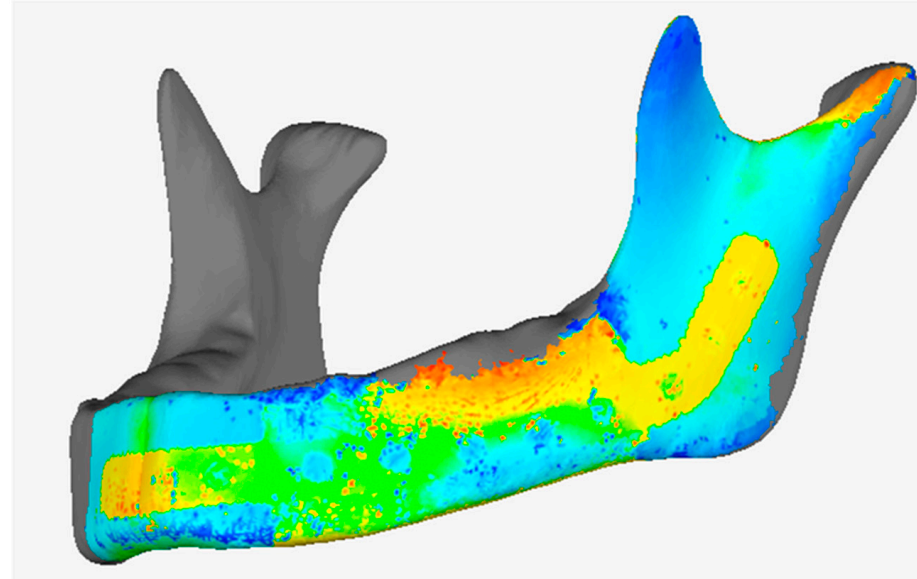

(a)

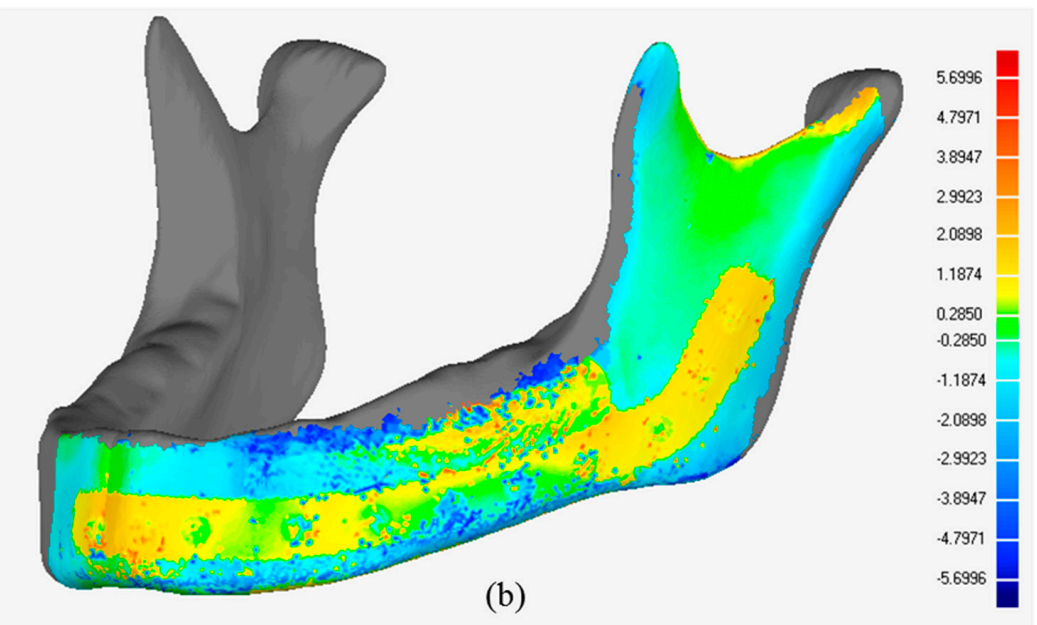

Figure 16. Evaluation of fitting deviation different designs: (a) Top and bottom porous; (b) inner porous.

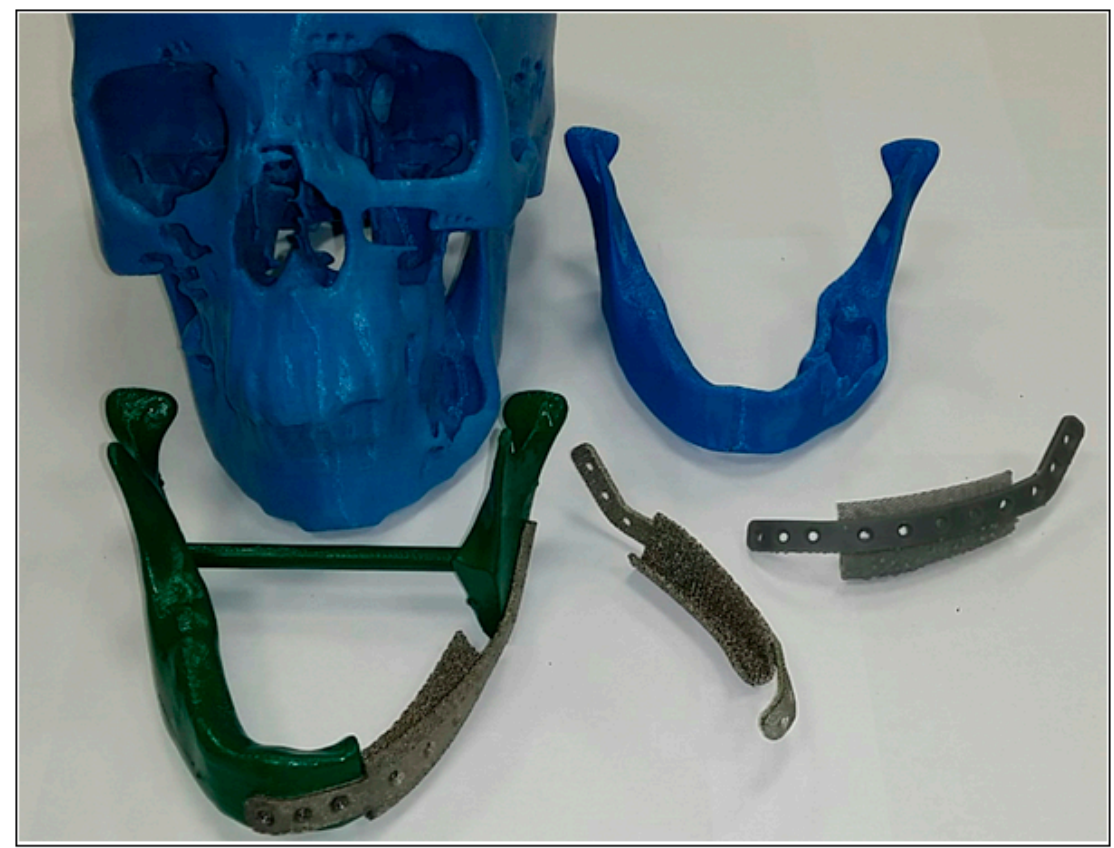

Figure 17. EBM and polymer fabricated mandibular framework models with prosthesis scaffolds. 


\section{Conclusions}

The success of mandibular reconstruction greatly depends on its aesthetics and biomechanical properties. It emphasizes the importance of the customized implants depending on the patient's anatomy. The custom designed implants provide a better option for mandible restoration than the generic counterpart as they can fit precisely on the patient's bone. The ability to 3D print custom designed scaffolds using EBM technology, providing surface texture conducive to tissue ingrowth makes them appropriate for the personalized implants with properties closer to that of bone. In this study, two customized scaffolds based on the inner porous plate as well as the top and bottom porous plate were designed, 3D printed and evaluated for structural integrity, weight and fitting accuracy. A competent methodology has been presented to acquire the customized, pleasing and reliable mandibular implants. The methodology was exhaustive comprising of data acquisition using $\mathrm{CT}$, mandible reconstruction as well as design, FEA, implant fabrication and testing.

Eventually, depending on the FEA, weight analysis and fitting accuracy evaluation, it can be inferred that the scaffold with the top and bottom porous plate is more favorable for bone reconstruction as compared to scaffold with the inner porous implant and can successfully be employed in the reconstruction of the defective mandible. Indeed, it can be asserted that the employment of prosthesis scaffolds in mandibular reconstruction satisfies the sustained need of lighter implants with accurate fitting and lesser surgical time and minimal revisions.

The customized porous implants are very effective and valuable because they provide an improved fit, enhanced osseointegration properties, lesser shielding effect and a higher implant stability. They strengthen the functional recovery of the mandibular deformities and maintain a graceful appearance on the mandible. It is mandatory that the research in this area should continue in the future for acquiring further innovative implant designs and reconstruction methods. The authors would like to expand this work by introducing new designs with different porous structures, and analyzing them for their strength and accuracy in mandible restoration. In addition, the authors would like to extend this work by including an extensive clinical (in-vivo) study in the future.

Author Contributions: K.M. conceived and designed the experiments; K.M. \& S.H.M. performed the experiments; U.U. helped in the analysis; H.A. analyzed the data; K.M. \& S.H.M. wrote and revised the paper.

Funding: This research was financially supported by Deanship of Scientific Research, King Saud University: Research group No. RG-1440-034.

Acknowledgments: The authors extend their appreciation to the Deanship of Scientific Research at King Saud University for funding this work through Research Group no. RG-1440-034.

Conflicts of Interest: The authors have no conflict of interest to declare.

\section{References}

1. Wong, R.C.W.; Tideman, H.; Kin, L.; Merkx, M.A.W. Biomechanics of mandibular reconstruction: a review. Int. J. Oral Maxillofac. Surg. 2010, 39, 313-319. [CrossRef]

2. Yan, R.; Luo, D.; Huang, H.; Li, R.; Yu, N.; Liu, C.; Hu, M.; Rong, Q. Electron beam melting in the fabrication of three-dimensional mesh titanium mandibular prosthesis scaffold. Sci. Rep. 2018, 8, 750. [CrossRef]

3. Miles, B.A.; Goldstein, D.P.; Gilbert, R.W.; Gullane, P.J. Mandible reconstruction. Curr. Opin. Otolaryngol. Head Neck Surg. 2010, 18, 317-322.

4. Hayden, R.E.; Mullin, D.P.; Patel, A.K. Reconstruction of the segmental mandibular defect: current state of the art. Curr. Opin. Otolaryngol. Head Neck Surg. 2012, 20, 231-236. [CrossRef]

5. Von Cramon-Taubadel, N. Global human mandibular variation reflects differences in agricultural and hunter-gatherer subsistence strategies. Proc. Natl. Acad. Sci. USA 2011, 108, 19546-19551. [CrossRef]

6. Yuan, J.; Cui, L.; Zhang, W.J.; Liu, W.; Cao, Y. Repair of canine mandibular bone defects with bone marrow stromal cells and porous $\beta$-tricalcium phosphate. Biomaterials 2007, 28, 1005-1013. [CrossRef] [PubMed]

7. Moiduddin, K. Implementation of Computer-Assisted Design, Analysis, and Additive Manufactured Customized Mandibular Implants. J. Med. Biol. Eng. 2018, 38, 744-756. [CrossRef] 
8. Chanchareonsook, N.; Junker, R.; Jongpaiboonkit, L.; Jansen, J.A. Tissue-engineered mandibular bone reconstruction for continuity defects: A systematic approach to the literature. Tissue Eng. Part B Rev. 2014, 20, 147-162. [CrossRef] [PubMed]

9. Ryan, G.; Pandit, A.; Apatsidis, D. Fabrication methods of porous metals for use in orthopaedic applications. Biomaterials 2006, 27, 2651-2670. [CrossRef] [PubMed]

10. Wang, X.; Xu, S.; Zhou, S.; Xu, W.; Leary, M.; Choong, P.; Qian, M.; Brandt, M.; Xie, Y.M. Topological design and additive manufacturing of porous metals for bone scaffolds and orthopaedic implants: A review. Biomaterials 2016, 83, 127-141. [CrossRef] [PubMed]

11. Moiduddin, K.; Al-Ahmari, A.; Kindi, M.A.; Nasr, E.S.A.; Mohammad, A.; Ramalingam, S. Customized porous implants by additive manufacturing for zygomatic reconstruction. Biocybern. Biomed. Eng. 2016, 36, 719-730. [CrossRef]

12. Pei, X.; Zhang, B.; Fan, Y.; Zhu, X.; Sun, Y.; Wang, Q.; Zhang, X.; Zhou, C. Bionic mechanical design of titanium bone tissue implants and 3D printing manufacture. Mater. Lett. 2017, 208, 133-137. [CrossRef]

13. Raghavendra, S.; Wood, M.C.; Taylor, T.D. Early wound healing around endosseous implants: a review of the literature. Int. J. Oral Maxillofac. Implant. 2005, 20, 425-431.

14. Singare, S.; Lian, Q.; Wang, W.P.; Wang, J.; Liu, Y.; Li, D.; Lu, B. Rapid prototyping assisted surgery planning and custom implant design. Rapid Prototyp. J. 2009, 15, 19-23. [CrossRef]

15. Emadabouel, N.; Abdulrahman, A.-A.; Khaja, M.; Al Kindi, M.; Kamrani, A. A digital design methodology for surgical planning and fabrication of customized mandible implants. Rapid Prototyp. J. 2016, 23, 101-109.

16. Chua, C.K.; Wong, C.H.; Yeong, W.Y. Standards, Quality Control, and Measurement Sciences in 3D Printing and Additive Manufacturing; Academic Press: London, UK, 2017.

17. Electron Beam Melting-EBM Process, Additive Manufacturing. Available online: http://www.arcam.com/ technology/electron-beam-melting/ (accessed on 7 July 2017).

18. Moiduddin, K.; Darwish, S.; Al-Ahmari, A.; El Watidy, S.; Mohammad, A.; Ameen, W. Structural and mechanical characterization of custom design cranial implant created using additive manufacturing. Electron. J. Biotechnol. 2017, 29, 22-31. [CrossRef]

19. Moiduddin, K.; Anwar, S.; Ahmed, N.; Ashfaq, M.; Al-Ahmari, A. Computer assisted design and analysis of customized porous plate for mandibular reconstruction. IRBM 2017, 38, 78-89. [CrossRef]

20. Narra, N.; Valášek, J.; Hannula, M.; Marcián, P.; Sándor, G.K.; Hyttinen, J.; Wolff, J. Finite element analysis of customized reconstruction plates for mandibular continuity defect therapy. J. Biomech. 2014, 47, 264-268. [CrossRef]

21. Liu, Y.; Fan, Y.; Jiang, X.; Baur, D.A. A customized fixation plate with novel structure designed by topological optimization for mandibular angle fracture based on finite element analysis. Biomed. Eng. Online 2017, 16, 131. [CrossRef]

22. Planmeca ProMax 3D Max-Dental Imaging to the Max. Available online: https://www.planmeca.com/ imaging/3d-imaging/planmeca-promax-3d-max/ (accessed on 09 April 2019).

23. Arango-Ospina, M.; Cortés-Rodriguez, C.J. Engineering design and manufacturing of custom craniofacial implants. In The 15th International Conference on Biomedical Engineering; Goh, J., Ed.; Springer International Publishing: Basel, Switzerland, 2014; pp. 908-911.

24. Zhou, L.; Shang, H.; He, L.; Bo, B.; Liu, G.; Liu, Y.; Zhao, J. Accurate Reconstruction of Discontinuous Mandible Using a Reverse Engineering/Computer-Aided Design/Rapid Prototyping Technique: A Preliminary Clinical Study. J. Oral Maxillofac. Surg. 2010, 68, 2115-2121. [CrossRef]

25. Van Bael, S.; Chai, Y.C.; Truscello, S.; Moesen, M.; Kerckhofs, G.; Van Oosterwyck, H.; Kruth, J.-P.; Schrooten, J. The effect of pore geometry on the in vitro biological behavior of human periosteum-derived cells seeded on selective laser-melted Ti6Al4V bone scaffolds. Acta Biomater. 2012, 8, 2824-2834. [CrossRef] [PubMed]

26. Ran, Q.; Yang, W.; Hu, Y.; Shen, X.; Yu, Y.; Xiang, Y.; Cai, K. Osteogenesis of 3D printed porous Ti6Al4V implants with different pore sizes. J. Mech. Behav. Biomed. Mater. 2018, 84, 1-11. [CrossRef] [PubMed]

27. Schaller, A.; Voigt, C.; Huempfner-Hierl, H.; Hemprich, A.; Hierl, T. Transient finite element analysis of a traumatic fracture of the zygomatic bone caused by a head collision. Int. J. Oral Maxillofac. Surg. 2012, 41, 66-73. [CrossRef]

28. El-Anwar, M.I.; Mohammed, M.S. Comparison between two low profile attachments for implant mandibular overdentures. J. Genet. Eng. Biotechnol. 2014, 12, 45-53. [CrossRef] 
29. Ti6Al4V ELI Titanium Alloy. 2014. Available online: http://www.arcam.com/wp-content/uploads/ArcamTi6Al4V-ELI-Titanium-Alloy.pdf (accessed on 27 January 2019).

30. Szucs, A.; Bujtár, P.; Sándor, G.K.B.; Barabás, J. Finite element analysis of the human mandible to assess the effect of removing an impacted third molar. J. Can. Dent. Assoc. 2010, 76, a72.

31. Simonovics, J.; Bujtár, P.; Váradi, K. Effect of preloading on lower jaw implant. Biomech. Hungarica 2013, 6, 21-28. [CrossRef]

32. What is FDM?: Fused Deposition Modeling Technology for 3D Printing | Stratasys n.d. Available online: https://www.stratasys.com/fdm-technology (accessed on 6 January 2019).

33. High Resolution SLA and SLS 3D Printers for Professionals. Formlabs n.d. Available online: https: //formlabs.com/ (accessed on 7 February 2019).

34. FDM vs SLA: How does 3D Printing Technology Work? |. Pinshape 3D Printing Blog | Tutorials, Contests \& Downloads 2017. Available online: https://pinshape.com/blog/fdm-vs-sla-how-does-3d-printer-tech-work/ (accessed on 7 February 2019).

35. Kumar, A.; Nune, K.C.; Murr, L.E.; Misra, R.D.K. Biocompatibility and mechanical behaviour of three-dimensional scaffolds for biomedical devices: Process-structure-property paradigm. Int. Mater. Rev. 2016, 61, 20-45. [CrossRef]

36. Horn, T.J.; Harrysson, O.L.A.; Marcellin-Little, D.J.; West, H.A.; Lascelles, B.D.X.; Aman, R. Flexural properties of Ti6Al4V rhombic dodecahedron open cellular structures fabricated with electron beam melting. Addit. Manuf. 2014, 1-4, 2-11. [CrossRef]

37. Murr, L.E.; Gaytan, S.M.; Medina, F.; Lopez, H.; Martinez, E.; Machado, B.I.; Hernandez, D.H.; Martinez, L.; Lopez, M.I.; Wicker, R.B.; Bracke, J. Next-generation biomedical implants using additive manufacturing of complex cellular and functional mesh arrays. Philos. Trans. R. Soc. A: Math. Phys. Eng. Sci. 2010, 368, 1999-2032. [CrossRef]

38. Tang, H.P.; Wang, J.; Song, C.N.; Liu, N.; Jia, L.; Elambasseril, J.; Qian, M. Microstructure, mechanical properties, and flatness of sebm Ti-6Al-4V sheet in as-built and hot isostatically pressed conditions. JOM 2017, 69, 466-471. [CrossRef]

39. Wang, M.; Li, H.Q.; Lou, D.J.; Qin, C.X.; Jiang, J.; Fang, X.Y.; Guo, Y.B. Microstructure anisotropy and its implication in mechanical properties of biomedical titanium alloy processed by electron beam melting. Mater. Sci. Eng. A 2019, 743, 123-137. [CrossRef]

40. Balza, J.C.; Zujur, D.; Gil, L.; Subero, R.; Dominguez, E.; Delvasto, P.; Alvarez, J. Sandblasting as a surface modification technique on titanium alloys for biomedical applications: abrasive particle behavior. IOP Conf. Ser. Mater. Sci. Eng. 2013, 45, 012004. [CrossRef]

41. Geomagic Control X. 3D Systems n.d. Available online: https://www.3dsystems.com/software/geomagiccontrol-x (accessed on 10 February 2019).

42. Hammad Mian, S.; Abdul Mannan, M.; M. Al-Ahmari, A. The influence of surface topology on the quality of the point cloud data acquired with laser line scanning probe. Sens. Rev. 2014, 34, 255-265. [CrossRef]

43. Ridtzwan, M.I.; Solehuddin, S.; Hassan, A.Y.; Shokri, A.A.; Mohamad Ibrahim, M.N. Problem of Stress Shielding and Improvement to the Hip Implant Designs: A Review. J. Med. Sci. 2007, 7, 460-467.

44. Soh, C.-K.; Yang, Y.; Bhalla, S. (Eds.) Smart Materials in Structural Health Monitoring, Control and Biomechanics; Springer-Verlag: Berlin, Germany, 2012.

45. Basciftci, F.A.; Korkmaz, H.H.; Üşümez, S.; Eraslan, O. Biomechanical evaluation of chincup treatment with various force vectors. Am. J. Orthod. Dentofac. Orthop. 2008, 134, 773-781. [CrossRef] [PubMed]

(C) 2019 by the authors. Licensee MDPI, Basel, Switzerland. This article is an open access article distributed under the terms and conditions of the Creative Commons Attribution (CC BY) license (http://creativecommons.org/licenses/by/4.0/). 